\title{
Reconhecimento de Línguas de Sinais: estudo comparado Brasil-Suécia
}

\author{
Recognition of Sign Language(s): comparative study Brazil-Sweden \\ Reconocimiento de lenguas de signos: estudio comparado Brasil-Suecia
}

\author{
Aline Lucia Baggio Montes \\ Professora mestra no Instituto Federal de São Paulo, Matão, São Paulo, Brasil. \\ alinelbaggio@gmail.com \\ ORCID - 0000-0002-5331-0737
}

\section{Cristina Broglia Feitosa de Lacerda}

Professora doutora na Universidade Federal de São Carlos, São Carlos, São Paulo, Brasil.

cbflacerda@gmail.com

ORCID - 0000-0002-3250-1374

Recebido em 6 de abril 2019

Aprovado em 13 de setembro de 2019

Publicado em 12 de novembro de 2019

\section{RESUMO}

O presente artigo apresenta dados de pesquisa sobre o reconhecimento de línguas de sinais e educação de surdos no Brasil e na Suécia. A análise investigou, na perspectiva comparada, as leis que reconhecem as línguas de sinais em ambos países. Trata-se de um estudo de abordagem qualitativa, do tipo documental, com dados de fontes primárias e tendo a análise de conteúdo como principal abordagem. Constatou-se que, na Suécia, o direito de aquisição e uso da língua sueca de sinais, como língua materna, está previsto na lei, e o país contribui efetivamente na criação de condições reais para a sua aquisição pela comunidade surda; as políticas linguísticas regem todo o processo de direito linguístico e de direito de aquisição de língua aos surdos. No Brasil, o direito à aquisição não é previsto em lei e, assim, não estão definidos os caminhos a serem percorridos pelas crianças surdas que almejam a aquisição de sua língua; os debates sobre a Libras sempre estiveram estritamente ligadas aos debates dos direitos da pessoa com deficiência, sendo evidente a dupla categorização dada aos surdos: pessoas com deficiência e membros de grupos minoritários. Após as análises dos textos das leis, podese concluir que o reconhecimento da Libras não garantiu ao surdos brasileiros o direito à aquisição da língua de sinais; e, também, não promoveu a garantia de uma educação bilíngue. Na Suécia, diante do cenário estudado, a lei só reafirmou a prática executada durante longos anos: uma educação em língua de sinais durante toda a idade escolar. Palavras-chave: Educação comparada; Reconhecimento de línguas de sinais; Brasil e Suécia.

\section{ABSTRACT}

This article presents research data on the recognition of sign languages and the education of the deaf in Brazil and Sweden. The analysis investigated, from a comparative perspective, the laws that recognize sign languages in both countries. It is a qualitative, 
documentary-type study with data from primary sources and content analysis as the main approach. It was found that in Sweden the right to acquire and use the Swedish language of signs as a mother tongue is provided for by law and the country effectively contributes to the creation of real conditions for acquisition by the deaf community; language policies govern the whole process of linguistic law and the right to acquire the language of the deaf. In Brazil, the right to acquisition is not provided for by law, and thus the paths to be covered by deaf children who seek acquisition of their language are not defined; the debates on Libras have always been closely linked to the debates on the rights of persons with disabilities, with the double categorization of the deaf being evident: people with disabilities and members of minority groups. After analyzing the texts of the laws, it can be concluded that the recognition of Libras did not guarantee the deaf people of Brazil the right to acquire sign language; and also did not promote the guarantee of a bilingual education. In Sweden, in view of the scenario studied, the law only reaffirmed the practice performed over many years: a sign language education throughout the school age.

Keywords: Comparative education; Recognition of sign language(s); Brazil and Sweden.

\section{RESUMEN}

El presente artículo presenta datos de investigación sobre el reconocimiento de lenguas de signos y educación de sordos en Brasil y Suecia. El análisis investigó, en la perspectiva comparada, las leyes que reconocen las lenguas de signos en ambos países. Se trata de un estudio de enfoque cualitativo, del tipo documental, con datos de fuentes primarias y teniendo el análisis de contenido como principal abordaje. Se constató que, en Suecia, el derecho de adquisición y uso de la lengua sueca de signos, como lengua materna, está previsto en la ley, y el país contribuye efectivamente a la creación de condiciones reales para su adquisición por la comunidad sorda; las políticas lingüísticas rigen todo el proceso de derecho lingüístico y de derecho de adquisición de lengua a los sordos. En Brasil, el derecho a la adquisición no está previsto en la ley y, por lo tanto, no están definidos los caminos a ser recorridos por los niños sordos que anhelan la adquisición de su lengua; los debates sobre Libras siempre estuvieron estrictamente vinculados a los debates de los derechos de la persona con discapacidad, siendo evidente la doble categorización dada a los sordos: personas con discapacidad y miembros de grupos minoritarios. Después de los análisis de los textos de las leyes, se puede concluir que el reconocimiento de la Libras no garantizó a los sordos brasileños el derecho a la adquisición de la lengua de signos; y tampoco promovió la garantía de una educación bilingüe. En Suecia, ante el escenario estudiado, la ley sólo reafirmó la práctica ejecutada durante largos años: una educación en lengua de signos durante toda la edad escolar.

Palabras clave: Educación comparada; Reconocimiento de lenguas de signos; Brasil y Suecia.

\section{Introdução e Metodologia}

O objetivo dessa pesquisa foi investigar, na perspectiva comparada, os documentos que reconhecem as línguas de sinais no Brasil e na Suécia. Optou-se por adotar a metodologia de estudos em educação comparada, que permite identificar semelhanças e 
http://dx.doi.org/10.5902/1984686X37656

diferenças no contexto indicado, ampliando o campo de análise e de compreensão da realidade nacional no confronto com outro(s) país(es).

Esta pesquisa consiste em um estudo de abordagem qualitativa, do tipo documental, com dados de fontes primárias. Para Marconi e Lakatos (2010), a principal característica da pesquisa documental é a fonte de coleta de dados, pois, nesse tipo de pesquisa, a fonte está restrita a documentos. A legislação de ambos os países sobre o reconhecimento e a oficialização da língua de sinais foi explorada. A partir das argumentações de Lacerda, Albres e Drago (2013), entende-se que

[...] os textos legais constituem importante campo de pesquisa; já que neles estão materializadas ideias e propostas de implementação de práticas que interferem diretamente na vida das pessoas, de modo que a melhor compreensão de tais textos pode colaborar [...] para o melhor atendimento dos sujeitos surdos (p. 69).

As autoras acrescentam que esse tipo de estudo se revela como fundamental no campo das políticas públicas, uma vez que "os documentos oficiais são instrumentos para a concretização dos direitos dos cidadãos" (LACERDA; ALBRES; DRAGO, 2013, p. 69).

Nessa perspectiva, considerando que a comparação com outro país nos faz refletir sobre nossas próprias práticas, o método comparativo, segundo Marconi e Lakatos (2010), realiza confrontações com a finalidade de verificar similitudes e explicar divergências entre tipos de grupos, sociedades ou povos, uma vez que "o método comparativo é usado tanto para comparações de grupos no presente, no passado, ou entre os existentes e os do passado, quanto entre sociedades de iguais ou de diferentes estágios de desenvolvimento" (p. 89).

A Suécia foi o primeiro país do mundo a dar status de língua a uma língua de sinais (BAGGA-GUPTA, 2010; SVARTHOLM, 2014); influenciando, por isso mesmo, processos de reconhecimento e educação de surdos em todo o mundo. Portanto, há um grande interesse acadêmico em conhecer o que há por trás desse reconhecimento da língua sueca de sinais e do "modelo sueco" de educação de surdos.

Assim, a opção metodológica para investigar os documentos que reconhecem as línguas de sinais nos dois países foi apoiada fundamentalmente em autores comparatistas tais como António Gomes Ferreira (2008), António Nóvoa (2009), Bob Adamson (2012), Ferran Ferrer Julià (1998, 2002).

Dessa forma, os dados identificados em cada país foram analisados e discutidos à luz da literatura. Por último, a conclusão traz comparações entre as duas realidades na 
http://dx.doi.org/10.5902/1984686X37656

tentativa de esclarecer as principais características, divergências e semelhanças entre a legislação brasileira e a sueca.

\section{Análises dos textos da Lei Libras (n010.436/2002) e da Lei da Língua Sueca (SFS2009:600)}

Nesta sessão, cada artigo, parágrafo e seção da Lei de Libras (n-10.346/2002) e da Lei da Língua Sueca (SFS 2009:600) será analisado.

O tratamento dos dados registrados se apoiou na abordagem de análise do conteúdo, a qual Bardin (2016) define como uma técnica de investigação científica que permite interpretações por meio de uma descrição objetiva e sistemática dos conteúdos de um determinado meio de comunicação. A etapa de análise dos documentos propõe-se a produzir ou reelaborar conhecimentos, criando novas formas de compreender os fenômenos.

\section{Lei de Libras}

A lei de reconhecimento da Libras dispõe sobre a língua brasileira de sinais e dá outras providências. Em seu primeiro artigo, afirma que:

Art. 1o É reconhecida como meio legal de comunicação e expressão a Língua Brasileira de Sinais - Libras e outros recursos de expressão a ela associados.

Parágrafo único. Entende-se como Língua Brasileira de Sinais - Libras a forma de comunicação e expressão, em que o sistema lingüístico de natureza visual-motora, com estrutura gramatical própria, constituem um sistema lingüístico de transmissão de idéias e fatos, oriundos de comunidades de pessoas surdas do Brasil. (BRASIL, 2002)

O reconhecimento da Libras, segundo Santana (2003), legitima o surdo como sujeito de linguagem. Além de trazer algumas implicações linguísticas e cognitivas, muda a maneira como a sociedade o vê, transformando a concepção de pessoa "anormal" para "diferente". Todavia, a própria lei, que em si aporta um caráter de ampliação do respeito à surdez e à pessoa surda, é redutora quando define a Libras como forma de "comunicação" e "expressão" de comunidades surdas brasileiras, pois se refere apenas à função comunicativa da língua, restringindo, de certa forma, a língua a um tipo de código de comunicação. Nesse sentido, o surdo não é deslocado efetivamente para uma posição de membro de uma comunidade linguística minoritária e com direitos próprios, 
http://dx.doi.org/10.5902/1984686X37656

permanecendo marcas na maneira de compreendê-lo como uma "pessoa com deficiência".

Rodrigues (2015), ao analisar a Lei de Libras, destaca a definição que a lei traz sobre o que é Libras e isso a diferencia de outras leis. Em relação à língua portuguesa, a autora destaca que a Constituição Federal afirma, no artigo 13, que "a língua portuguesa é o idioma oficial da República Federativa do Brasil” (BRASIL, 1988). O artigo não acrescenta nenhum tipo de explicação adicional. Já no texto da Lei de Libras, encontra-se uma explicação do que seja a língua, que de um lado é uma explicação parcial e insuficiente das características de uma língua de sinais e, de outro, parece indicar a necessidade do legislador de afirmar que se trata de uma língua, transparecendo uma não convicção em relação a isso. Dessa forma, a lei não reconhece a Libras como língua, e, sim, como "meio legal de comunicação e expressão", a reduzindo a uma forma de comunicação, uma ferramenta a ser utilizada.

Uma explicação plausível para esse fato é que no Brasil impera, desde a época da colonização, a ideia de nação monolíngue, que persiste até os dias atuais.

Nesse viés, Oliveira (2009) destaca que no período pós independência foram instauradas políticas linguísticas homogeneizadoras em todo território nacional, o que ocasionou um verdadeiro glotocídio. Assim, das 1.078 línguas faladas no ano de 1500, apenas 180 línguas ainda resistem. O autor destaca que

poderíamos ter sido um país ainda muito mais plurilíngüe, não fossem as repetidas investidas do Estado (e das instituições aliadas, ou ainda a omissão de grande parte dos intelectuais) contra a diversidade cultural e lingüística. [...] Não fomos apenas um país multicultural e plurilíngüe: somos um país pluricultural e multilíngue [...] (OLIVEIRA, 2009, p. 24).

A língua portuguesa se constitui como instrumento de poder, contribuindo para uma prática monolíngue de "utilizar a primeira língua do aluno para 'acabar' rapidamente com ela, com o objetivo de 'alcançar' a língua oficial” (SKLIAR, 2013, p. 10). Nesse viés, a surdez é vista como uma deficiência auditiva. Logo, se esta deficiência é superada, a língua portuguesa poderá ser adquirida. Assim, a surdez é marcada por ausências e privações, contexto em que o discurso médico "normalizante" também ganha destaque. Contudo, deveria ser pensada como uma experiência visual, "[...] uma diferença a ser politicamente reconhecida" (SKLIAR, 2013, p. 11).

Uma miríade de línguas que se mesclam faz parte da história das diferentes nações. No Brasil, pela história de colonização, massacre dos povos indígenas - primeiros 
brasileiros - e imposição da língua do dominador, o mito do monolinguismo se consolidou e a história contemporânea se encarregou de apagar as disputas linguísticas retratadas ao longo dos anos. Há erroneamente a concepção de que se fala uma única língua, a língua portuguesa. Para esta concepção, ser brasileiro e falar o Português (do Brasil) são sinônimos. Oliveira (2009) afirma que,

[...] No nosso caso, produziu-se o "conhecimento" de que no Brasil se fala o português, e o "desconhecimento" de que muitas outras línguas foram e são igualmente faladas. $O$ fato de que as pessoas aceitem, sem discutir, como se fosse um fato natural, que o português é a língua do Brasil foi e é fundamental, para obter consenso das maiorias para as políticas de repressão às outras línguas, hoje minoritárias (p. 19-20).

A primeira política linguística que ganhou destaque em território brasileiro foi promovida pelo Marquês de Pombal no documento denominado Diretório dos Índios, cujo objetivo era legislar sobre a vida dos índios após à expulsão dos Jesuítas. Neste sentido, civilizar os índios significava, claramente, impor o português.

Além dos índios, os imigrantes e seus descendentes também sofreram violenta repressão linguística. No regime ditatorial, instaurado por Getúlio Vargas, os imigrantes foram proibidos de usar línguas maternas, como o italiano e o alemão, inviabilizando a livre circulação dessas línguas, principalmente nos estados de Santa Catarina e Rio Grande do Sul (OLIVEIRA, 2009).

Vemos que, ao longo da história, há um apagamento da diversidade linguística brasileira. Atualmente, quando uma língua - diferente da língua portuguesa - precisa ganhar respeito e visibilidade, o processo torna-se um tanto quanto conflituoso. Essa outra língua, por sua vez, não pode ser reconhecida como uma "língua", e é vista como "meio de comunicação e expressão" (no caso da Libras), a fim de não colocar em risco o mito da língua única. E, para reforçar sua legitimidade, precisa mostrar o detalhamento de sua configuração para que não haja dúvidas sobre sua definição.

Lei de Libras. Art. 2o Deve ser garantido, por parte do poder público em geral e empresas concessionárias de serviços públicos, formas institucionalizadas de apoiar o uso e difusão da Língua Brasileira de Sinais Libras como meio de comunicação objetiva e de utilização corrente das comunidades surdas do Brasil. (BRASIL, 2002)

Sobre o "uso" da língua, é proporcionado à comunidade surda o direito de usar a Libras nas empresas concessionárias de serviços públicos e, portanto, a lei promove a garantia de ter atendidas as necessidades sociais por meio da mediação pela Libras. A presença do profissional intérprete de línguas de sinais ganha destaque, já que até aquele 
http://dx.doi.org/10.5902/1984686X37656

momento somente a língua portuguesa era utilizada nesses espaços. Essa ação demanda contratação e/ou vínculo empregatício do profissional intérprete, e as discussões relacionadas à sua formação, que até o momento não haviam sido assumidas oficialmente, são retomadas.

Esse artigo da lei, portanto, enfatiza a necessidade de serviços que proporcionem uma forma de "acessibilidade" aos surdos. Assim, ações formativas nesse viés e a presença de intérpretes de línguas de sinais começam a ganhar espaço. $O$ primeiro documento que contemplou a atuação e formação desse profissional foi a Lei da Acessibilidade, no 10.098/2000, que estabeleceu normas gerais e critérios básicos para a promoção da acessibilidade das pessoas com deficiência ou com mobilidade reduzida (BRASIL, 2000).

Com a regulamentação da Lei de Libras por meio do Decreto no 5.626 em 2005, o termo tradutor e intérprete de Libras/língua portuguesa (TILSP) e a determinação da formação desse profissional em nível superior aparece pela primeira vez; assim como ações para a "difusão" da Libras.

Uma das ações, nesse aspecto, é a criação do bacharelado em Letras/Libras, inicialmente oferecido na modalidade a distância pela Universidade Federal de Santa Catarina (UFSC). Todavia, ganha fomento ampliado com o programa Viver sem Limites, durante o governo da presidente Dilma Rousseff (2011 - 2016) e passa a receber incentivos para a modalidade presencial, sendo, a partir de então, apoiada a criação de cursos de bacharelado em Letras/Libras em instituições federais de ensino superior. Atualmente, há sete cursos em nível superior oferecidos por universidades federais brasileiras: Universidade Federal de Santa Catarina (UFSC); Universidade Federal de Goiás (UFG); Universidade Federal de Roraima (UFRR); Universidade Federal do Rio de Janeiro (UFRJ); Universidade Federal do Espírito Santo (UFES); Universidade Federal do Rio Grande do Sul (UFRGS) e Universidade Federal de São Carlos (Ufscar), no estado de São Paulo, de acordo com dados do portal do Ministério da Educação e Cultura (MEC).

Além da formação de professores e de tradutores e intérpretes de Libras/língua portuguesa, a difusão da Libras pode ser vista na mídia, em programas que contam com janelas em Libras, programas estatais, ensino de Libras, entre outros.

Lei de Libras. Art. 3 s instituições públicas e empresas concessionárias de serviços públicos de assistência à saúde devem garantir atendimento e tratamento adequado aos portadores de deficiência auditiva, de acordo com as normas legais em vigor. (BRASIL, 2002) 
http://dx.doi.org/10.5902/1984686X37656

O tradicional atendimento prestado a pessoas com deficiência no setor médicoclínico permanece para os deficientes auditivos; ou melhor, para aqueles que assim se veem. Todavia, a lei enfatiza o direito linguístico para aqueles que dele quiserem se valer.

Esse artigo também pode ser visto como uma maneira de evitar possíveis conflitos com aqueles que apoiam a corrente "oralista"; ou seja, aqueles que afirmam que o necessário à pessoa surda é aprender a falar e ter ampliados seus recursos auditivos. Assim, o direito é garantido para os que quiserem manter essa perspectiva. Portanto, o artigo atende a uma minoria sem se indispor com outros grupos.

Lei de Libras. Art. 4ㅇ sistema educacional federal e os sistemas educacionais estaduais, municipais e do Distrito Federal devem garantir a inclusão nos cursos de formação de Educação Especial, de Fonoaudiologia e de Magistério, em seus níveis médio e superior, do ensino da Língua Brasileira de Sinais - Libras, como parte integrante dos Parâmetros Curriculares Nacionais - PCNs, conforme legislação vigente. (BRASIL, 2002)

A Lei de Libras foi propulsora de várias conquistas para a comunidade surda. Entre elas, pode-se destacar a obrigatoriedade legal da disciplina de Libras na educação superior como uma das ações concretas dessa política, assim como a necessidade de dar visibilidade à língua, para que cidadãos não surdos saibam que existe uma língua de sinais e que esta deve ser respeitada. Um lugar para se fazer isso é na formação universitária de futuros professores - nos cursos de licenciatura - que poderão ter alunos surdos, considerando a política de inclusão de alunos com deficiência (e surdos) nas escolas comuns.

A política mais recente que versa sobre a inclusão dos alunos com deficiência é a Lei no 13.146 de 6 de julho de 2015 (BRASIL, 2015), também conhecida como Estatuto da Pessoa com Deficiência. Essa lei dedica um capítulo para o direito à educação e prevê que cabe "ao poder público assegurar, criar, desenvolver, implementar, incentivar, acompanhar e avaliar" um "sistema educacional inclusivo em todos os níveis e modalidades" (BRASIL, 2015, Art. 28, inciso I). Para os alunos surdos, a lei garante "oferta de educação bilíngue, em Libras como primeira língua e na modalidade escrita da língua portuguesa como segunda língua, em escolas e classes bilíngues e em escolas inclusiva" (BRASIL, 2015, Art. 28, inciso IV).

No que se refere ao ensino superior, a lei prevê "acesso à educação superior e à educação profissional e tecnológica em igualdade de oportunidade e condições com as demais pessoas" (BRASIL, 2015, Art. 28, inciso XIII). Portanto, ampliando as 
http://dx.doi.org/10.5902/1984686X37656

possibilidades de que um professor venha a ter um aluno com deficiência no ensino superior. Caso esse aluno seja surdo, a referida lei garante a disponibilização de tradutores e intérpretes de Libras, a fim de promover a "acessibilidade para todos os estudantes [...] aos ambientes e às atividades concernentes a todas as modalidades, etapas e níveis de ensino" (BRASIL, 2015, Art. 28, inciso XVI).

Assim, além da visibilidade, a disciplina de Libras tem como objetivo ensinar fundamentos da língua de sinais para aqueles que vão atuar diretamente no ensino. Nesse sentido, Rodrigues e Quadros (2015) acrescentam:

\begin{abstract}
Quando um professor da disciplina de Libras passa a compor o quadro das universidades brasileiras, principalmente nos cursos de licenciatura e de Fonoaudiologia, para abordar a Língua de Sinais, há o desencadeamento de um consistente processo de transformação social, política, cultural e acadêmica. A presença da Libras como disciplina curricular contribui com a mudança da realidade das línguas no país, até então definido em termos monolíngues: o Português é a única língua do Brasil. Assim, temos a visibilização da Libras e a construção de uma nova consciência capaz de entender o fato de termos várias línguas indígenas e de imigrantes que vivem no Brasil, dentre outras (CAVALCANTI, 1996). Isso é um ganho surdo, pois o fato de existir uma Lei que reconhece uma língua, que não o Português, como língua nacional abre espaço para o reconhecimento oficial de todas as línguas faladas no Brasil como línguas nacionais (p. 82).
\end{abstract}

A partir do momento em que se insere a obrigatoriedade do ensino de Libras em currículos acadêmicos, busca-se uma formação adequada para aceitação e uso da Libras como língua, no diálogo e interações com a comunidade surda. Esse seria mais um passo para a inclusão dos surdos na sociedade.

Em contrapartida, o interesse pelo modelo educacional inclusivo é tão forte que a Lei de Libras reserva um de seus cinco artigos para o ensino da Libras nos cursos de formação de professores, ficando subentendido que, dessa forma, o futuro profissional terá melhores condições para atender o aluno surdo. Há, portanto, um foco maior no ensino da Libras para os ouvintes do que para a própria comunidade surda.

A referida lei não prevê o direito das pessoas surdas de aprender/ter acesso à Libras desde a mais tenra idade, que seria um direito linguístico por excelência. $O$ desenvolvimento cognitivo linguístico da criança surda depende fortemente de sua exposição/contato o mais cedo possível a uma língua de sinais acessível a ela, e esse direito primordial não é garantido na lei. Nesse sentido, uma política de Estado que favoreça o acesso à Libras para a população surda é visivelmente necessária. 
http://dx.doi.org/10.5902/1984686X37656

Lei Libras. Parágrafo único. A Língua Brasileira de Sinais - Libras não poderá substituir a modalidade escrita da língua portuguesa. (BRASIL, 2002)

A importância da língua portuguesa se mantém e, então, a comunidade surda deverá ser necessariamente bilíngue, usuária de sua língua de sinais e da língua majoritária, na modalidade escrita. É uma questão, também, de constitucionalidade à lei; sem isso ela não teria valor.

Assim, o decreto que regulamenta a Lei de Libras aponta que a escola será responsável pelo ensino na modalidade escrita da língua majoritária, mostrando os caminhos e os espaços onde essa educação deverá ser implantada

São denominadas escolas ou classes de educação bilíngue aquelas em que a Libras e a modalidade escrita da Língua Portuguesa sejam línguas de instrução utilizadas no desenvolvimento de todo o processo educativo (BRASIL, 2005, Artigo 22, § 1ㅇ).

E, também, reforça a necessidade de profissionais com formação para atuarem no ensino-aprendizagem da modalidade escrita da língua portuguesa:

O ensino da modalidade escrita da Língua Portuguesa, como segunda língua para as pessoas surdas, deve ser incluído como disciplina curricular nos cursos de formação de professores para a educação infantil e para os anos iniciais do ensino fundamental, de nível médio e superior, bem como nos cursos de licenciatura em Letras com habilitação em Língua Portuguesa (BRASIL, 2005, Artigo 13).

Para a efetivação do bilinguismo, "numa escola ou programa bilíngue, os estudantes devem ter a oportunidade de aprender a sua segunda língua de acordo com o ensino apropriado de segunda língua" (SVARTHOLM, 2014, p. 43). Esse trabalho exige que o professor não somente tenha conhecimentos das duas línguas, suas estruturas e características; como também tenha formação pedagógica e metodológica baseada em conhecimentos linguísticos das duas línguas.

Lei de Libras. Art. 5o Esta Lei entra em vigor na data de sua publicação. (BRASIL, 2002)

Devido aos direcionamentos necessários para sua efetivação, a Lei de Libras foi regulamentada pelo Decreto n 5.626, de 2005 (BRASIL, 2005). O decreto, na verdade, indica caminhos para cada um dos aspectos abordados na lei. Trata da inclusão da Libras como disciplina curricular; da formação do professor e do instrutor de Libras; do uso e difusão da Libras e da língua portuguesa para o acesso das pessoas surdas à educação; da formação do tradutor e intérprete de Libras/Língua Portuguesa; do direito à educação e 
http://dx.doi.org/10.5902/1984686X37656

à saúde e do papel do poder público e das empresas que detêm concessão ou permissão de serviços públicos, no apoio ao uso e difusão da Libras.

A Lei da Libras possui, portanto, uma intensa trajetória político-ideológica pautada na organização dos movimentos sociais surdos e na ruptura da visão patológica da surdez. Todavia, apesar dos avanços, deixa algumas questões importantes de fora e não enfatiza os direitos linguísticos dos surdos, principalmente no que diz respeito ao acesso à língua. Em nenhum artigo essa questão foi mencionada.

\section{Lei da Língua Sueca}

Na Suécia, a Lei da Língua reconhece, além do sueco, a língua sueca de sinais e outras línguas minoritárias.

$\S 1^{0}$ Esta lei contém disposições sobre a língua sueca, as línguas de minorias e a língua sueca de sinais. A lei também inclui disposições sobre a responsabilidade do estado para que cada pessoa possa ter acesso à língua assim como sobre o uso da língua em atividades públicas e contextos internacionais. (SFS 2009:600)

O parágrafo inicial da lei faz uma apresentação das línguas que serão abordadas. Apesar do nome Lei da Língua Sueca, a lei abrange, também, as línguas minoritárias e a língua sueca de sinais.

A Suécia, como pode ser observado, não possui uma legislação específica para o reconhecimento de sua língua de sinais. Ao contrário, utiliza a mesma lei para reconhecer o sueco - como principal língua da Suécia - e algumas línguas minoritárias nacionais; proporcionando, assim, um visível status à língua sueca de sinais, quando a coloca no mesmo patamar das demais línguas.

O papel do Estado também ganha destaque nesse parágrafo, sendo de sua responsabilidade a criação de condições para o acesso da população às línguas nacionais. O acesso está estritamente ligado à aquisição das línguas relativas a cada comunidade, enfatizando, assim, o direito linguístico de cada cidadão sueco. Ainda nesse viés, o uso da língua em atividades públicas e contextos internacionais pode ser visto como direito ao acesso.

Lei da Língua Sueca. $\S 2^{\circ}$ O objetivo da lei é indicar a posição e o uso da língua sueca e de outras línguas na sociedade sueca. A lei também protege a língua sueca e a pluralidade linguística na Suécia, além do acesso das pessoas à língua. (SFS 2009:600) 
Fica claro que o propósito desse parágrafo é indicar o objetivo da lei, "alertando" que será abordada a posição e o uso da língua sueca na sociedade, assim como a posição e o uso de outras línguas. Portanto, subentende-se que cada língua terá seu papel e/ou função na sociedade, talvez com alguns privilégios diferentes.

Além disso, define lugar/papel social das línguas reconhecidas na Suécia; defende a pluralidade linguística e trata o sueco no conjunto das línguas de sinais e de minorias nacionais. Trata-se de uma lei das línguas e, portanto, todas estão aqui descritas. Ainda que cada uma tenha valor social diferente, o fato de a lei ser única para o conjunto das línguas usadas no país deve ser destacado, por indicar um certo respeito à pluralidade linguística.

Lei da Língua Sueca. $\S$ 3o Se houver alguma outra lei ou decreto que contenha alguma disposição que divirja desta lei, a referida disposição será considerada válida. (SFS 2009:600)

É bem provável que possa existir a necessidade de disposições específicas de outras leis ou regulamentos, já que a lei de uma língua possui um escopo amplo e o texto previsto na lei pode estar sujeito a limitações.

Um exemplo de lei que fornece uma proteção ainda maior para qualquer um dos idiomas que a Lei da Língua Sueca inclui como línguas minoritárias é a Lei Sobre Minorias Nacionais e Línguas Minoritárias (SFS 2009:724). Aprovada depois da Lei da Língua Sueca, prevê os direitos dos indivíduos, usuários das línguas minoritárias reconhecidas na Suécia; significando, assim, uma maior proteção para essas línguas. Além disso, essas leis específicas podem ser vistas como uma forma de normatizar as ações, as disposições gerais que estão expressas na Lei da Língua Sueca.

Lei da Língua Sueca. § 4ํㅜ A língua sueca é a língua principal da Suécia. (SFS 2009:600)

A partir dos objetivos da política linguística e dessa lei, esse parágrafo proporciona ao sueco uma posição especial de principal língua da Suécia. Nesse sentido, pode-se perguntar por que o termo "principal" foi eleito, ao invés de uma outra terminologia. Talvez porque o termo de "língua principal" enfatize a importância da língua sueca e dá sinais de que o sueco é a língua falada pela maioria dos habitantes do país; todavia, deixando subentendido que há outras línguas a serem consideradas.

Nesse mesmo sentido, o termo "língua nacional" também não foi utilizado na lei. Uma explicação seria o fato de a expressão criar a ideia de que se refere a uma 
http://dx.doi.org/10.5902/1984686X37656

linguagem associada a uma identidade nacional, sem ser necessariamente a língua mais utilizada ou a língua materna mais comum. Além disso, as demais línguas reconhecidas são, por sua vez, também línguas nacionais. Assim, talvez a opção pelo termo "principal" foi mostrar que o sueco recebe um destaque em relação às demais línguas, ainda que ocupem o mesmo patamar.

Portanto, a partir do reconhecimento estabelecido nessa lei, as línguas minoritárias nacionais e a língua sueca de sinais podem ser consideradas como línguas oficiais e nacionais.

Lei da Língua Sueca. § 5 Como língua principal, o sueco é a língua comum da sociedade a que todos que moram na Suécia devem ter acesso e que deve ser usada dentro de todas as regiões da sociedade. (SFS 2009:600)

Esse parágrafo aponta o sueco como uma língua comum a todos. Implica uma obrigação da sociedade em garantir oportunidades para o aprendizado do sueco, devendo ser utilizado em todos os domínios da sociedade e nas relações internacionais. A língua sueca, portanto, é vista como a língua de trânsito comum entre todos os cidadãos suecos.

Apesar de a lei apoiar o ensino e a difusão das diferentes línguas, a língua sueca é a que recebe maior prestigio, e, também, é aquela que deve ser aprendida por todos os cidadãos suecos.

Lei da Língua Sueca. § 60 O estado é o principal responsável pela utilização e pelo desenvolvimento da língua sueca. (SFS 2009:600)

Quando se refere ao Estado, trata-se do Parlamento, governo, governos locais e demais organismos envolvidos em atividades públicas.

Nesse parágrafo, são mencionados termos como "utilização" e "desenvolvimento". Todavia, ao se referir às línguas minoritárias e à língua sueca de sinais, como será visto nos parágrafos 8 § e 9 §, a lei destaca a responsabilidade especial do Estado de "proteger e promover" essas línguas.

Dessa forma, os termos equivalentes não são utilizados para a língua sueca. Entretanto, isso não deve ser interpretado no sentido de que o sueco não será protegido e promovido. Ao contrário, o status de língua principal e de uso em relações internacionais indica uma proteção ainda mais abrangente, já que é principalmente por meio da utilização que a língua se desenvolve e transpassa gerações. 
http://dx.doi.org/10.5902/1984686X37656

Lei da Língua Sueca. $\S 7^{0}$ As línguas nacionais das minorias são 0 finlandês, o ídiche, o finlandês tornedaliano (meänkieli), o români (romani chib) e o sâmi (samiska). (SFS 2009:600)

As línguas identificadas como minorias nacionais, na Suécia, são línguas abrangidas pela Convenção do Conselho da Europa sobre a Proteção das Minorias Nacionais. O finlandês, o finlandês tornedaliano e o sâmi possuem laços históricos e geográficos com a Suécia, enquanto o ídiche e o români são vistos como línguas minoritárias territoriais, com proteção mais geral.

Esses idiomas são reconhecidos como de minorias nacionais e existem na Suécia há três gerações, pelo menos, sendo considerados como pertencentes ao patrimônio cultural da Suécia (SOU 2008:26).

A inclusão das línguas minoritárias na Lei da Língua é um efeito positivo e melhoria de status e promoção da sobrevivência dos idiomas, garantindo o aumento da sua visibilidade perante a sociedade sueca.

Em contrapartida, a língua de sinais não é reconhecida na mesma seção das demais línguas minoritárias nacionais. Por possuir características diferentes, será contemplada em outro parágrafo específico. O relatório de investigação apresentado pelo Comitê das Línguas (SOU 2006:54) usou como argumento o fato de a língua de sinais não ser considerada como a língua de um povo, língua de etnia ou territorial. Assim, para o relatório, a surdez não é vista como uma diferença cultural.

Lei da Língua Sueca. § 8으 O estado tem a responsabilidade especial de proteger e promover as línguas nacionais das minorias. (SFS 2009:600)

Em geral, "proteger e promover" línguas significa não proibir ou impedir sua utilização; ressaltando algumas medidas ativas para sua promoção e preservação em todo território nacional, como: revisão de métodos e recursos, desenvolvimento tecnológico de materiais de apoio, criação de condições para gerações futuras aprenderem a língua, entre outros.

Essas medidas ativas vão além do ensino das línguas minoritárias. A promoção da língua é realizada na vida cultural, na televisão e em sites com informações oficiais; sendo essas e outras ações de reponsabilidade do Instituto de Língua e Folclore ${ }^{1}$ (Institutet för Spräk och Folkminnen).

O mesmo ocorre em relação à língua de sinais. Colocar a língua em circulação para que novos cidadãos possam adquirir/aprender e se desenvolver a partir dela é uma das responsabilidades desse instituto. 
http://dx.doi.org/10.5902/1984686X37656

Nesse sentido, a Lei Sobre Minorias Nacionais e Línguas Minoritárias (SFS 2009:724) proporciona maior respaldo para esse parágrafo. Ela contém disposições sobre minorias nacionais, línguas minoritárias nacionais, áreas administrativas e o direito de utilizar línguas minoritárias perante as autoridades administrativas e nos tribunais; bem como disposições sobre determinadas funções pré-escolares e atividades educativas referidas no capítulo 25 da Lei da Educação (SFS 2010:800). Assim, o Estado deve destinar recursos para que o acesso às línguas minoritárias seja garantido aos seus usuários.

Lei da Língua Sueca. §9으 $\mathrm{O}$ estado tem a responsabilidade principal de proteger e promover a língua sueca de sinais. (SFS 2009:600)

O parágrafo enfatiza a necessidade de o Estado destinar recursos a fim de garantir o acesso à língua de sinais.

A língua sueca de sinais é uma das várias línguas minoritárias reconhecidas nessa lei, e é desenvolvida e utilizada na Suécia. É de responsabilidade do Estado sua "proteção" e "promoção", da mesma forma que está previsto para as línguas nacionais minoritárias.

Como pode ser visto, essa lei trata da língua sueca de sinais e das línguas nacionais minoritárias em seções diferentes. Isso acontece porque a língua sueca de sinais não foi incluída quando a Suécia assinou a Convenção do Conselho da Europa sobre a Proteção das Minorias Nacionais. O Comitê de Ministros criado em 2003, de acordo com recomendações do Conselho da Europa, para elaborar regras específicas sobre os direitos dos usuários de língua de sinais, destaca que ela não estava abrangida no objetivo geral da Convenção Linguística Minoritária: apoiar as línguas históricas como um patrimônio cultural, e como parte do patrimônio multicultural da Europa. O comitê ressaltou que a função da língua de sinais não é principalmente cultural, mas sim um meio de comunicação para surdos e, portanto, estaria fora do propósito principal da convenção. Sublinhou, ainda, que não havia motivos para estender e adaptar as disposições da convenção à língua de sinais, por já possuir status oficial como língua na Suécia.

Os surdos, por sua vez, são suecos, nasceram no país e, por isso, não há território a defender ou demarcar. Devido à restrição auditiva, as línguas orais não são acessíveis, e essa seria uma das principais diferenças que marca esse grupo. Sem a língua de sinais, o desenvolvimento cognitivo ficaria prejudicado, e o acesso à língua oral-auditiva (sueco ou 
http://dx.doi.org/10.5902/1984686X37656

qualquer outra) seria quase que inexistente. Em contrapartida, os usuários de línguas minoritárias nacionais possuem fácil acesso às demais línguas orais auditivas, como à língua sueca. A diferença está na luta por disputas territoriais, culturais, por direitos específicos. Portanto, as línguas marcam as diferenças históricas de cada grupo, que, por guerras ou pressões sociais, se deslocaram territorialmente, e, assim, precisam preservar sua identidade linguística cultural.

No relatório final, o comitê enfatizou que a proteção oferecida à língua de sinais precisa ser diferente da proteção disponível para as línguas minoritárias nacionais. No relatório, os motivos para isso são apresentados da seguinte forma:

\begin{abstract}
Ao contrário do patrimônio cultural associado às línguas minoritárias faladas, o bilinguismo do surdo pode ser considerado mais como monocultural, já que a língua de sinais transmite a mesma cultura que a língua sueca. A maioria das pessoas que usam língua sueca de sinais para a sua comunicação nasceu na Suécia. O patrimônio cultural e as tradições dos pais, irmãos e familiares de usuários de língua de sinais são, muitas vezes, os mesmos da maioria da sociedade. Ao fazê-lo, o status de língua minoritária da língua sueca de sinais é menos consistente com a Convenção, cujo principal objetivo é proteger e promover o idioma como base para a preservação de um patrimônio cultural.

A Lei sobre minorias nacionais e línguas minoritárias enfatiza o valor do multilinguismo e que a promoção de uma língua nacional ou minoritária não ultrapassa a língua oficial do país. As pessoas pertencentes a uma minoria histórica nacional são obrigadas a aprender e usar as línguas oficiais do país em alguns contextos, quando necessário. O objetivo da língua minoritária é que, de acordo com a Convenção do Conselho da Europa sobre a Proteção das Minorias Nacionais, as minorias nacionais devem ter o direito de manter e desenvolver a sua cultura e os elementos essenciais da sua identidade, como a religião, a língua, as tradições e o património cultural. No caso dos surdos, surdos-cegos e deficientes auditivos; estes não conseguem aprender as línguas faladas por causa da perda auditiva, apenas isso. (SOU 2006:54, seção 5.7).
\end{abstract}

Nesse viés, o relatório de investigação das línguas na Suécia (SOU 2008:26), que antecedeu a Lei da Língua Sueca, pesquisou questões relacionadas à língua de sinais. $O$ relatório afirma que a língua de sinais sueca também deve ser reconhecida numa posição de direito público na sociedade sueca, correspondente à posição das cinco línguas minoritárias.

De acordo com o relatório, a língua de sinais precisa de um suporte semelhante ao oferecido às línguas das minorias nacionais na Convenção Linguística Minoritária, se equiparando às línguas faladas (SOU 2008:26).

O relatório enfatiza, ainda, que a Suécia - como membro do Conselho da Europa deve trabalhar em busca de uma convenção ou estatuto que dê às línguas de sinais europeias uma posição equivalente às línguas minoritárias. Assim, no âmbito das Nações 
http://dx.doi.org/10.5902/1984686X37656

Unidas e da Convenção Sobre os Direitos das Pessoas com Deficiência, a Suécia deve trabalhar para garantir o fortalecimento da língua de sinais, considerando os direitos de seus usuários (SOU 2008:26).

É perceptível, assim, a influência do Conselho da Europa nas decisões e ações tomadas pela Suécia, por ser membro ativo.

Lei da Língua Sueca. $\S 10$ A língua oficial dos tribunais, autoridades administrativas e demais entidades que atuam como atividades públicas é a língua sueca.

Em outra lei há disposições especiais sobre o direito de utilização de línguas nacionais das minorias e de outra língua nórdica.

No que se refere à obrigação por parte de tribunais e autoridades administrativas quanto à contratação de intérpretes e tradução de documentos, há disposições específicas. (SFS 2009:600)

A primeira parte da seção destaca, mais uma vez, o papel de "língua principal" ocupado pela língua sueca, em todo e qualquer tipo de atividade, e em todas as áreas da sociedade, categoricamente. A segunda parte refere-se ao direito de uso de línguas minoritárias nacionais, conforme a Lei Sobre Minorias Nacionais e Línguas Minoritárias (SFS 2009:724) e Convenção Nórdica de Assistência Social e Serviços Sociais (SFS 1995:479). E, por último, há disposições específicas sobre a contratação de intérpretes e tradução de documentos para as minorias nacionais.

No caso de usuários de línguas minoritárias ou de língua sueca de sinais precisarem de serviços específicos mediante tribunais ou demais autoridades administrativas, cabe a estas repartições a contratação de intérpretes para esses fins. Além disso, para atender às necessidades específicas dos usuários das línguas minoritárias nacionais, a tradução de um documento também é de responsabilidade dessas repartições.

Lei da Língua Sueca. $§ 11 \mathrm{~A}$ linguagem usada para atividades públicas deve ser aprimorada, objetiva e inteligível. (SFS 2009:600)

Essa seção faz a exigência ao setor público de uma linguagem simples, sem palavras enigmáticas e compreensível a todos os cidadãos. Isso é importante ao se considerar as razões democráticas e de segurança jurídica, aplicando-se, assim, à língua escrita e à falada. Esse debate volta-se sobre o sueco enquanto língua democrática.

Lei da Língua Sueca. § 12 As autoridades têm uma responsabilidade especial para que a terminologia sueca, dentro de suas áreas de especialização, seja acessível, tenha utilização e possa ser desenvolvida. (SFS 2009:600) 
http://dx.doi.org/10.5902/1984686X37656

Para que o sueco seja utilizado em todas as áreas, devem existir terminologias atualizadas para cada especificidade. Há agências governamentais voltadas para a concretização desse objetivo.

Lei da Língua Sueca. $§ 13$ A língua sueca é o idioma oficial da Suécia em contextos internacionais.

A posição do idioma sueco como idioma oficial da União Europeia tem que ser protegida. (SFS 2009:600)

A língua sueca é utilizada nas relações internacionais tanto por escrito quanto verbalmente. Esse critério atende plenamente aos princípios exigidos pela União Europeia.

Lei da Língua Sueca. § 14 Qualquer pessoa que more na Suécia tem que ter a possibilidade de aprender, aprimorar e usar o sueco. Além disso:

1. Qualquer pessoa que pertença a uma minoria nacional tem que ter a possibilidade de aprender, aprimorar e usar a língua da minoria, e

2. Qualquer pessoa que seja surda ou sofra de deficiência auditiva, ou qualquer pessoa que por qualquer outro motivo precise recorrer à língua de sinais, tem que ter a possibilidade de aprender, aprimorar e usar a língua sueca de sinais.

Qualquer pessoa que tenha outra língua materna além daquelas mencionadas no primeiro parágrafo tem que ter a possibilidade de aprimorar e usar sua língua materna. (SFS 2009:600)

Nesse parágrafo, as oportunidades de "aprender", "aprimorar" e "usar" dizem respeito ao sueco, às línguas minoritárias nacionais e à língua sueca de sinais.

Assim, "qualquer pessoa que seja surda" ou, ainda, "qualquer pessoa que por algum outro motivo precise recorrer à língua de sinais" (nesse caso, podemos mencionar familiares, profissionais diversos) tem a possibilidade de aprender, aprimorar e usar a língua sueca de sinais. Nesse viés, o surdo tem o direto de adquirir e usar a língua de sinais como língua materna.

Em relação às outras pessoas, que tenham uma língua materna diferente das mencionadas, a lei prevê a possibilidade de "aprimorar" e "usar" sua língua materna. A possibilidade de "aprender" não é prevista, assumindo a existência de um conhecimento prévio do idioma. Portanto, um indivíduo com língua materna diferente das citadas na seção já deve possuir um conhecimento da língua para, só então, ter acesso à educação.

Diante disso, a seção parece deixar de fora os filhos de pais que têm uma língua materna diferente das línguas minoritárias reconhecidas pela lei. Essa restrição está de acordo com os termos dos chamados "educação na língua materna hoje": a língua materna de um aluno deve ser a linguagem de comunicação diária do aluno para que o 
http://dx.doi.org/10.5902/1984686X37656

município seja obrigado a oferecer educação em língua materna, conforme está previsto na Ordem das Escolas Básicas (SFS 1994: 1194).

Lei da Língua Sueca. $\S 150$ estado é responsável para que qualquer pessoa tenha acesso à língua, conforme o parágrafo 14. (SFS 2009:600)

A seção enfatiza a responsabilidade do Estado em proporcionar a todos o acesso à língua. Portanto, ao terminar o parágrafo ressaltando "conforme parágrafo 14", fica entendido que o acesso diz respeito não só ao sueco, como também às línguas minoritárias nacionais e à língua sueca de sinais.

Vimos, portanto, que a Lei da Língua Sueca aborda toda a situação linguística na Suécia, por se tratar de uma lei linguística em geral, conforme categorias definidas por De Meulder (2015). O objetivo geral da lei é estabelecer o status da língua sueca e, também, de línguas minoritárias na sociedade, a fim de proteger a língua sueca e sua diversidade linguística. Ela representa, por sua vez, uma espécie de "obrigação", ditando o que a sociedade deve e precisa fazer, e não uma lei de direitos aos cidadãos suecos. Essas obrigações são ressaltadas ao longo das seções, e dizem respeito a todas as línguas reconhecidas por essa lei.

\section{Considerações finais}

A educação comparada, enquanto metodologia no contexto do presente estudo nos ajudou a visualizar e refletir sobre questões que, se vistas isoladamente, poderiam causar estranheza em relação à possibilidade de compará-las. Brasil e Suécia tiveram seus trajetos marcados por traços bem singulares.

$\mathrm{Na}$ Suécia, a função da língua de sinais não é cultural, mas sim uma língua constitutiva que favorece o desenvolvimento dos surdos, que são vistos, primeiramente, como suecos; o direito de aquisição e uso da língua sueca de sinais, como língua materna, está previsto na lei, e o país contribui efetivamente na criação de condições reais para a sua aquisição pela comunidade surda; as políticas linguísticas regem todo o processo de direito linguístico e de direito de aquisição de língua aos surdos. No Brasil, em contrapartida, estudiosos da área e a comunidade surda defendem que os surdos possuem uma língua definida por ideias, crenças, costumes e hábitos de um povo, se referindo a ele como "povo surdo"; o direito à aquisição não é previsto em lei e, assim, não estão definidos os caminhos a serem percorridos pelas crianças surdas que almejam a aquisição de sua língua; os debates sobre a Libras sempre estiveram estritamente 
http://dx.doi.org/10.5902/1984686X37656

ligadas aos debates dos direitos da pessoa com deficiência, sendo evidente a dupla categorização dada aos surdos: pessoas com deficiência e membros de grupos minoritários. Portanto, o reconhecimento da Libras não garantiu aos surdos brasileiros o direito à aquisição da língua de sinais; e, também, não promoveu a garantia de uma educação bilíngue. Na Suécia, diante do cenário estudado, a lei só reafirmou a prática executada durante longos anos: uma educação efetiva em língua de sinais durante toda a idade escolar.

\section{Referências}

ADAMSON, Bob. International comparative studies. Teaching and Teacher Education, v. 28, p. 641-648, 2012. Disponível em: http://media.journals.elsevier. com/content/files/s0742051x12000340-04221112.pdf. Acesso em: 06 nov. 2017.

BAGGA-GUPTA, Sangeeta. Creating and (Re)negotiating Boundaries: Representations as Mediation in Visually Oriented Multilingual Swedish School Settings. Language, Culture and Curriculum. v. 23, p. 251-76, 2010.

BARDIN, Laurence. Análise de conteúdo. São Paulo: Edições 70, 2016.

BRASIL. Constituição da República Federativa do Brasil. Brasília, DF: Senado Federal: Centro Gráfico, 1988. 292 p.

BRASIL. Decreto no 5.626, de 22 de dezembro de 2005. Regulamenta a Lei n 10.436, de 24 de abril de 2002, que dispõe sobre a Língua Brasileira de Sinais - Libras, e o art. 18 da Lei n 10.098, de 19 de dezembro de 2000. Brasília, Diário Oficial da União, 23 dez. 2005.

BRASIL. Lei no 10.098, de 19 de dezembro de 2000. Lei da Acessibilidade. Estabelece normas gerais e critérios básicos para a promoção da acessibilidade das pessoas portadoras de deficiência ou com mobilidade reduzida, e dá outras providências. Brasília, Diário Oficial da União, 20 dez. 2000, Seção 1, Eletrônico, p. 2.

BRASIL. Lei no 10.436, de 24 de abril de 2002. Lei da Língua Brasileira de Sinais; Lei de Libras (Língua Brasileira de Sinais). Dispõe sobre a Língua Brasileira de Sinais - Libras e dá outras providências. Brasília, Diário Oficial da União, 25 abr. 2002, Seção 1, p. 23.

BRASIL. Lei no 13.146, de 6 de julho de 2015. Estatuto da Pessoa com Deficiência. Lei Brasileira de Inclusão da Pessoa com Deficiência. Institui a Lei Brasileira de Inclusão da Pessoa com Deficiência (Estatuto da Pessoa com Deficiência). Brasília, Diário Oficial da União, 7 jul. 2015, Seção 1, p. 2.

DE MEULDER, Maartje. The legal recognition of sign languages. Sign Language Studies. v. 15, n. 4, p. 498-506, 2015. 
FERREIRA, António Gomes. O sentido da educação comparada: uma compreensão sobre a construção de uma identidade. Educação, Porto Alegre, v. 31, n. 2, p. 124-138, maio/ago. 2008. Disponível em:

http://revistaseletronicas.pucrs.br/ojs/index.php/faced/article/view/2764. Acesso em 06 nov 2017.

JULIÀ, Ferran Ferrer. La Educación Comparada Actual. Barcelona: Ariel, 2002.

LACERDA, Cristina Broglia Feitosa de; ALBRES, Neiva de Aquino; DRAGO, Silvana Lucena dos Santos. Política para uma educação bilíngue e inclusiva a alunos surdos no município de São Paulo. Educação \& Pesquisa, São Paulo, v. 39, n.1, p. 65-80, jan./mar. 2013.

MARCONI, Marina de Andrade; LAKATOS, Eva Maria. Fundamentos de metodologia científica. 7. ed. São Paulo: Atlas, 2010.

NÓVOA, António. Modelos de análise de educação comparada: o campo e o mapa. In: SOUZA, Donaldo Bello de; MARTINEZ, Silvia Alicia (Orgs). Educação comparada: rotas de além-mar. SP: Xamã, 2009.

OLIVEIRA, Gilvan Müller de. Plurilinguismo no Brasil: repressão e resistência linguística. Synergies Brésil, n. 7, 2009, p. 19-26.

RODRIGUES, Carlos Henrique; QUADROS, Ronice Müller. Diferenças e linguagens: a visibilidade dos ganhos surdos na atualidade. Revista Teias, Rio de Janeiro, v. 16, n. 40, 2015.

RODRIGUES, Fernanda dos Santos Castelano. Politicas linguísticas e educacionais envolvendo a Libras (Mesa redonda). COLÓQUIO LÍNGUA, DISCURSO E PODER: AS LÍNGUAS DE SINAIS NOS ESTUDOS DA LINGUAGEM, 1. São Carlos, Universidade Federal de São Carlos/SP, 2015.

SANTANA, Ana Paula. O. Reflexões neurolingüísticas sobre a surdez. 2003. 312 p. Tese (Doutorado) - Linguística - Instituito de Estudos da Linguagem, Universidade Estadual de Campinas, Campinas/SP, 2003.

SKLIAR, Carlos. Os estudos surdos em educação: problematizando a normalidade. In: SKLIAR, Carlos. (Orgs). A surdez: um olhar sobre as diferenças. 6. ed. Porto Alegre: Mediação, 2013. p. 7-32.

SUÉCIA. SFS 1994:1194. Grundskoleförordning. Svensk författningssamling. Utbildningsdepartementet.

SUÉCIA. SFS 1995:479. Nordisk konvention om socialt bistånd och sociala tjänster.

SUÉCIA. SFS 2009:600. Språklag. Svensk författningssamling. Kulturdepartementet.

SUÉCIA. SFS 2009:724. Nationella minoriteter och minoritetsspråk. Svensk författningssamling. Kulturdepartementet. 
http://dx.doi.org/10.5902/1984686X37656

SUÉCIA. SFS 2010:800. Skollag. Svensk författningssamling. Utbildningsdepartementet.

SUÉCIA. SOU 2006:54. Teckenspråk och teckenspråkiga Översyn av teckenspråkets ställning. Till statsrådet och chefen för ocialdepartementet.

SUÉCIA. SOU 2008:26. Värna språken: förslag till språklag. Betänkande av Språklagsutredningen.

SVARTHOLM, Kristina. 35 anos de Educação Bilíngue de surdos - e então? Educar em Revista, Curitiba, Edição Especial n.2, p. 33-50, 2014.

\section{Notas finais}

1 Para mais informações, cf.: http://www.sprakochfolkminnen.se.2 Antonio Campos de Abreu, Karin Lilian Strobel (LANNA JUNIOR, 2010).

\section{Correspondência}

Aline Lucia Baggio Montes - Instituto Federal de São Paulo, IFSP, Campus Matão, Rua Stéfano D'Avassi, 625, Nova Cidade, Matão, SP - Brasil.

CEP: 15991-502

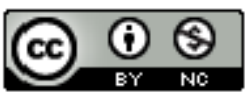

This work is licensed under a Creative Commons Attribution-NonCommercial 4.0 International (CC BY-NC 4.0) 